\title{
Serum lactate as a predictor of mortality after paediatric cardiac surgery
}

\author{
M Hatherill, T Sajjanhar, S M Tibby, M P Champion, D Anderson, M J Marsh, \\ I A Murdoch
}

\begin{abstract}
Objective-To assess the value of sequential lactate measurement in predicting postoperative mortality after surgery for complex congenital heart disease in children.

Design-Prospective observational study. Setting-Sixteen bedded paediatric intensive care unit (PICU).

Subjects-Ninety nine children ( 90 survivors, nine non-survivors).

Measurements-Serum lactate and base deficit were measured on admission and every six hours thereafter. Data were analysed by Mann-Whitney and Fisher's exact tests.

Results-There was considerable overlap in initial lactate values between the survivor and non-survivor groups. Initial lactate was significantly raised in nonsurvivors (median 8.7, range 1.9-17.6 mmol/1) compared with survivors (median 2.4, range 0.6-13.6 $\mathrm{mmol} / 1)(\mathrm{p}=$ $0.0002)$. Twenty one patients $(21.1 \%)$ with initial lactate concentrations greater than $4.5 \mathrm{mmol} / 1$ survived to PICU discharge. Using receiver operating characteristic analysis an initial lactate of $6 \mathrm{mmol} / 1 \mathrm{had}$ the optimum predictive value for mortality. Initial postoperative serum lactate $>6 \mathrm{mmol} / 1$ predicted mortality with sensitivity $78 \%$, specificity $83 \%$, and positive predictive value of only $32 \%$.

Conclusion-Initial lactate concentrations have poor positive predictive value for mortality. The routine measurement of lactate for this purpose cannot be justified in clinical practice.

(Arch Dis Child 1997;77:235-238)
\end{abstract}

Keywords: cardiac surgery; lactate; mortality

Paediatric Intensive Care Unit, 9th Floor, Guy's Hospital, St Thomas's Street, London SE10 8JA M Hatherill

T Saijanhar

S M Tibby

M P Champion

D Anderson

M J Marsh

I A Murdoch

Correspondence to: Dr Hatherill.

Accepted 5 June 1997 et al found that an initial lactate greater than $4.5 \mathrm{mmol} / 1$ had a positive predictive value for mortality of $100 \% .^{5}$ This has not been our experience. In a pilot study of paediatric cardiac surgical cases we found that an initial lactate concentration above $4.5 \mathrm{mmol} / 1$ had a positive predictive value for mortality of only $16.7 \%{ }^{7}$

We report the findings of a prospective observational study of sequential serum lactate measurement after complex paediatric cardiac surgery.

\section{Patients and methods}

Ninety nine patients (90 survivors/nine nonsurvivors) admitted to the paediatric intensive care unit (PICU) at Guy's Hospital after surgery for complex congenital heart disease, ${ }^{8}$ were enrolled into the study over the period December 1995 to July 1996 (see table 1). Patients falling into the lowest category of complexity, including those undergoing procedures such as atrial septal defect repair, patent ductus arteriosus ligation and Blalock-Taussig shunt, were not enrolled.

At our institution the cardiopulmonary bypass pump prime comprised a mixture of blood and synthetic colloid. Not more than 25-100 $\mathrm{ml}$ of Hartmann's solution was added, so that the pump prime itself was not a significant source of extraneous lactate. Full cardiopulmonary bypass flows were calculated at 1.6-2.4 1/min $\times$ body surface area. The total cardiopulmonary bypass time (minutes) was recorded for each patient.

Anaesthetic technique varied according to the anaesthetist, but no routine adjunctive medication, such as $\beta$ blockade, or 'deep anaesthesia' was used. Central venous lines, pacing wires, and peritoneal dialysis catheters were routinely placed at operation. All surgical procedures were performed by the same cardiac surgeon (DA) over the study period. Patients were transferred directly to the PICU immediately after surgery. After admission, the majority of patients were paralysed and sedated over the first 12 hours, using morphine 10-20 $\mu \mathrm{g} / \mathrm{kg} / \mathrm{hour}$ and vecuronium $80-120 \mu \mathrm{g} / \mathrm{kg} / \mathrm{min}$.

Serum lactate $(\mathrm{mmol} / \mathrm{l})$, arterial $\mathrm{pH}$, and base deficit $(\mathrm{mmol} / \mathrm{l})$ were measured immediately on admission to the PICU and at six, 12, 18 , and 24 hours. Lactate was analysed using the Yellowstone Instruments YSI 2300 STAT plus analyser. Outcome measures were postoperative complications and survival to discharge from the PICU. related to postoperative complications and mortality in adults and children. ${ }^{3-6}$ Recently, in a series of children after cardiac surgery, Siegel 
Table 1 Categories of surgical complexity (based on fenkins et al ${ }^{8}$ ), surgical procedures, mortality, and initial serum lactate

\begin{tabular}{|c|c|c|c|c|}
\hline Category & Procedure & No $(\%)$ & No (\%) died & $\begin{array}{l}\text { Median (range) } \\
\text { lactate (mmolll) }\end{array}$ \\
\hline IV & $\begin{array}{l}\text { Arterial switch }(n=9) \\
\text { Fontan procedure }(n=5) \\
\text { Hypoplastic left heart syndrome }(n=7)(\text { Norwood stage } 1)\end{array}$ & $21(21.2)$ & $4(19.0)$ & $4.9(1.0-17.6)$ \\
\hline III & $\begin{array}{l}\text { Truncus arteriosus }(n=2) \\
\text { Pulmonary homograft }(n=15) \\
\text { Aortic homograft }(n=19) \\
\text { Glenn procedure }(n=7)\end{array}$ & $43(43.4)$ & $4(9.3)$ & $2.4(0.6-17.0)$ \\
\hline II & $\begin{array}{l}\text { Ventricular septal defect }(n=17) \\
\text { Atrioventricular septal defect }(n=9) \\
\text { Fallot's tetralogy }(n=9)\end{array}$ & $35(35.3)$ & $1(2.8)$ & $2.0(0.8-11.5)$ \\
\hline
\end{tabular}

Postoperative complications were categorised into two groups: group 1-those that might reflect end organ damage, including liver dysfunction, requirement for peritoneal or haemodialysis, and seizures and group 2 -other cardiac or mechanical, including atrial or ventricular arrhythmias, reintubation in the PICU, and reopening/failure to close the chest. For the purposes of correlation with lactate, a 'complicated postoperative course' was defined as the presence of any complication in group 1.

Routine serial measurement of lactate and acid-base parameters constituted standard practice in the PICU at that time, and therefore informed consent was not obtained. Each blood sample comprised $0.6 \mathrm{ml}$ in total.

Data were assumed non-parametric and analysed by Mann-Whitney test, Spearman's rank correlation, and Fisher's exact test. Prognostic data were displayed graphically using receiver operating characteristic (ROC) analysis. ${ }^{9}$

\section{Results}

Data were analysed on 99 children, median age 5 months (range $0.38-31$ months). The distribution of complexity, mortality, and initial serum lactate is shown in table 1. Patients undergoing more complex surgery had significantly higher initial lactate concentrations $(\mathrm{p}=$ 0.0032 ). Median initial lactate was $2.4 \mathrm{mmol} / 1$ in the survivor group compared with 8.7 $\mathrm{mmol} / \mathrm{l}$ in the non-survivor group $(\mathrm{p}=0.0002)$ (see table 2). There was considerable overlap in lactate concentrations between the two groups. Initial lactate ranged from $0.6-13.6 \mathrm{mmol} / 1$ in survivors and from $1.9-17.6 \mathrm{mmol} / 1$ in the non-survivors. Twenty one children $(21.1 \%)$ with initial lactate greater than $4.5 \mathrm{mmol} / 1 \mathrm{sur}-$ vived to discharge from the PICU.

The postoperative course was complicated by seizures $(n=6)$, liver dysfunction $(n=15)$,

Table 2 Median postoperative serum lactate (mmol/l) in survivors $(n=90)$ and non-survivors $(n=9)$

\begin{tabular}{llllll}
\hline & \multicolumn{2}{l}{ Time (hours) } & & \\
\cline { 2 - 6 } & 0 & 6 & 12 & 18 & 24 \\
\hline Survivors & & & & & \\
$\quad$ Median & 2.4 & 1.3 & 1.0 & 1.1 & 0.9 \\
$\quad \begin{array}{l}\text { Range } \\
\text { Non-survivors }\end{array}$ & $0.6-13.6$ & $0.4-7.4$ & $0.4-4.6$ & $0.4-3.1$ & $0.4-2.7$ \\
$\quad$ Median & 8.7 & 5.6 & 2.9 & 2.4 & 3.6 \\
$\quad$ Range & $1.9-17.6$ & $2.0-17.1$ & $1.1-15.2$ & $1.3-11.0$ & $1.3-11.1$ \\
p Value & 0.0002 & 0.0002 & 0.0009 & 0.0005 & 0.0004 \\
\hline
\end{tabular}

^ By Mann-Whitney. dialysis $(n=15)$, reintubation $(n=7)$, arrhythmias $(n=13)$, inability to close the sternum ( $n$ $=5$ ), and reopening of the chest in nine patients. Median initial lactate was $6.1 \mathrm{mmol} / \mathrm{l}$ (range 0.8-17.6) in the complicated group compared with $2.2 \mathrm{mmol} / 1$ (range 0.6-13.0) in the uncomplicated group ( $\mathrm{p}<0.0001)$.

\section{PROGNOSTIC VALUE}

ROC analysis was employed to determine the optimum cut off for prediction of mortality, and an initial lactate concentration of $6 \mathrm{mmol} / \mathrm{l}$ was found to be optimum, with a sensitivity of $78 \%$, specificity of $83 \%$, and positive predictive value of only $32 \%$. An initial lactate level above $6 \mathrm{mmol} / \mathrm{l}$ predicted complications with a sensitivity of $50 \%$, specificity of $90 \%$, and positive predictive value of $68 \%$.

The median initial base deficit was -5.4 $\mathrm{mmol} / 1$ (range -2.8 to -16.3 ) in non-survivors compared with $-2.25 \mathrm{mmol} / 1$ (range -1.5 to $-8.6)$ in survivors $(p=0.049)$. The presence of a metabolic acidosis, as reflected by a base deficit worse than $-4 \mathrm{mmol} / \mathrm{l}$, was not significantly associated with non-survival. Indeed, ROC analysis of severity of base deficit revealed no consistent optimum cut off value (see fig 1). The combination of metabolic acidosis with hyperlactataemia did not improve the predictive value for mortality - the presence of lactate greater than $6 \mathrm{mmol} / 1$ plus base deficit worse than $4 \mathrm{mmol} / 1$ had a sensitivity of $75 \%$, specificity of $92 \%$, and positive predictive value of only $38 \%$.

The median total cardiopulmonary bypass time was significantly longer in non-survivors

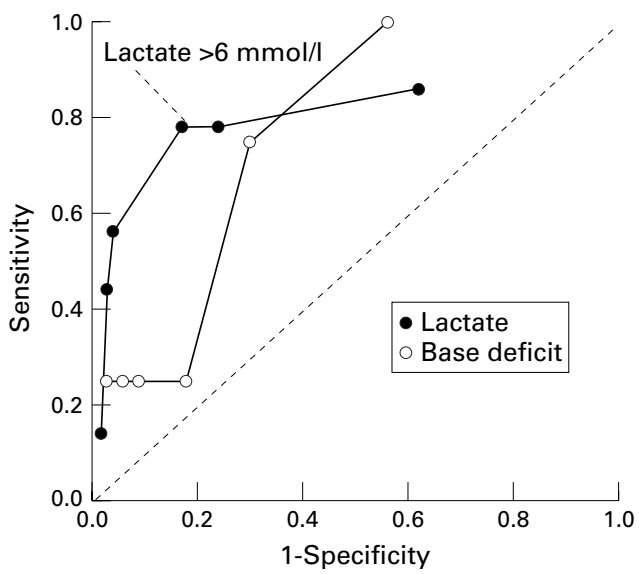

Figure 1 ROC curve showing sensitivity and (1specificity) of initial serum lactate and base deficit for mortality. 
(101 $\mathrm{min})$ than survivors $(73 \mathrm{~min})(\mathrm{p}=$ $0.0125)$. Although total cardiopulmonary bypass time correlated with the serum lactate concentration with statistical significance, the $r$ value was low ( $r=0.23$, Spearman's rank correlation) and this was not thought to have clinical significance. Similarly, patients with an initial lactate greater than $6 \mathrm{mmol} / \mathrm{l}$ had a median total cardiopulmonary bypass time of $86 \mathrm{~min}$, which was not significantly longer than those with lower lactate concentrations (73.5 $\min )$.

\section{Discussion}

Initial postoperative serum lactate concentrations have been used to predict outcome in paediatric practice. Siegel et al reported a series of 41 children who underwent open cardiac surgery with cardiopulmonary bypass. ${ }^{5}$ Mean lactate concentrations in survivors were 2.4 $\mathrm{mmol} / 1$ (range 1.1-4.2) compared with 6.9 $\mathrm{mmol} / 1$ (range 3.9-10.2) in non-survivors. Subsequently, Shemie reported the relationship between serum lactate and complicated outcome in 109 children after cardiopulmonary bypass. ${ }^{6}$ Mean (SD) admission lactate in non-survivors was $13.7(8.9) \mathrm{mmol} / \mathrm{l}$ compared with 6.8 (3.7) $\mathrm{mmol} / \mathrm{l}$ in survivors. Lactate concentrations greater than $5 \mathrm{mmol} / \mathrm{l}$ were associated with $75 \%$ sensitivity and $84 \%$ specificity for complications.

In contrast to the work of these groups, our results reflect a broad overlap in initial postoperative serum lactate between survivors and non-survivors. Indeed, while previous workers have found an initial lactate greater than 4.5 $\mathrm{mmol} / 1$ to be $100 \%$ predictive of mortality, ${ }^{5}$ $21.1 \%$ of our patients had such a hyperlactataemia, yet survived to discharge from the PICU. Our patient group appears to be a representative sample of children requiring cardiac surgery for correction of complex congenital heart disease, in terms of severity of the underlying condition, surgical complexity, and mortality rates. ${ }^{8}$ Overall mortality rates in other comparable groups were $17 \%$ and $7.3 \%$ respectively. $^{56}$

There are several confounding issues in the use of postoperative serum lactate to reflect mortality. We may not simply assume that hyperlactataemia reflects global tissue hypoxia and therefore tissue injury, as hyperlactataemia results from a net imbalance between production and hepatic clearance. ${ }^{10-12}$ Even if serum lactate were a consistent, accurate reflection of tissue hypoxia, it is limitation of tissue oxygen extraction despite increased oxygen delivery, not decreased oxygen supply per se, that is most closely related to mortality in critical illness. ${ }^{13}$ Moreover, studies have shown that critical oxygen supply limitation to the hepatosplanchnic circulation may occur at levels of global oxygen delivery which remain adequate for other tissue beds. ${ }^{10}{ }^{14}$

There are several other variables related to perfusion technique and anaesthetic method which may influence the immediate postoperative lactate concentration, such as duration of total circulatory arrest, the depth of intraopera- tive anaesthesia and pain relief, ${ }^{15}$ and the use of adjunctive medication such as phenoxybenzamine and esmolol. ${ }^{16}$

We are unable to explain the improved survival in our group of patients with raised lactate, but it suggests that postoperative hyperlactataemia not only reflects intraoperative tissue oxygen debt and hepatic clearance, but also variations in practice between cardiac surgeons, anaesthetists, perfusionists, and paediatric intensivists.

The findings of previous groups suggest that lactate concentrations could be used in routine clinical practice as a predictor of postoperative mortality. We do not agree; although the 'optimum' prognostic lactate value determined by ROC analysis $(6 \mathrm{mmol} / \mathrm{l})$ had reasonably high sensitivity and specificity, the positive predictive value was only $32 \%$ because of low mortality. Initial postoperative serum lactate cannot be considered a 'good' predictor of mortality in this group of patients.

Some advocate the use of base deficit as a prognostic parameter. Although the initial base deficit was worse in non-survivors compared with survivors, the presence of a clinically relevant base deficit was not associated with non-survival. The combination of variables reflecting metabolic acidosis with hyperlactataemia did not significantly improve predictive value for mortality.

Although initial lactate correlated with total bypass time, the low $r$ value suggests that this relationship is not clinically important. As patients with a severe hyperlactataemia ( $>6$ $\mathrm{mmol} / \mathrm{l}$ ) did not have a significantly longer bypass time, we speculate that the raised lactate, and hence the underlying tissue oxygen debt, may be related not to the duration of bypass, but to hypoperfusion during the cooling and rewarming phases.

The overall rate of group 1 (end organ) complications was $24.2 \%$, which compares with complication rates of $29.3 \%{ }^{6}$ and multisystem organ failure rates of $26.8 \%$ reported in previous studies. ${ }^{5}$ Since peritoneal dialysis catheters are placed routinely at operation in the majority of our patients, our unit has a relatively low threshold for the institution of dialysis for oliguria or severe acidosis. Therefore a dialysis rate of $15 \%$ in this group of patients might be higher than at other institutions. We were surprised that only $6 \%$ of our patient group manifested clinical evidence of seizures.

The fact that hyperlactataemia $(>6 \mathrm{mmol} / \mathrm{l})$ appears to be a good indicator of complications (positive predictive value 68\%) probably reflects end organ hypoperfusion damage. This supports the work of Shemie. ${ }^{6}$

\section{Conclusion}

Initial serum lactate varies widely among both survivors and non-survivors after surgery for complex congenital heart disease in children. Initial lactate concentrations are a poor predictor of mortality and the routine measurement of serum lactate for this purpose cannot be justified. However, serum lactate may prove to be 
a useful indicator of postoperative complications. The use of base deficit is of no value in predicting mortality.

1 Squara P, Journois D, Formela JF, Schremmer B, Dhainaut JF, Bleichner G. Value of elementary, combined, and modelled hemodynamic variables. 7 Crit Care 1994;9:223-35.

2 Balakrishnan G, Aitchison T, Hallworth D, Morton NS. Prospective evaluation of the paediatric risk of mortality (PRISM) score. Arch Dis Child 1992;67:196-200.

3 Abramson D, Scalea TM, Hitchcock R, et al. Lactate clearance and survival following injury. $\mathcal{F}$ Trauma 1993;35:5849 .

4 Marnitz U, Dauberschmidt R, Mrochen $\mathrm{H}$. The value of blood lactate determination in the post-operative phase blood lactate determination in the post-opera

5 Siegel L, Hauser G, Hertzog J, Hopkins R, Hannan R, Dalton $H$. Initial post-operative serum lactate predicts outcome in children after open heart surgery. Crit Care Med 1995; 23(suppl 1):A205.

6 Shemie S. Serum lactate predicts post-operative complications after pediatric cardiac surgery. Pediatr Res 1996;39. 54A:307.

7 Sajianhar T, Tibby SM, Hatherill M, Anderson D, Murdoch IA. Useful or useless: sequential lactate levels following correction of complex congenital heart disease. Intensive Care Medicine 1996;22(suppl 3):S282.
8 Jenkins K, Newburger J, Lock J, Davis R, Coffman G, Iezzoni L. In-hospital mortality for surgical repair of congenital heart defects: preliminary observations of
tion by hospital caseload. Pediatrics 1995;95:323-30.

9 Altman D. Practical statistics for medical research. London: Altman D. Practical statistics for
Chapman and Hall, 1991: 417-8.

10 Landow L. Splanchnic lactate production in cardiac surgery patients. Crit Care Med 1993;21:S84-91.

11 Taylor KM, Bain WH, Russell M, Brannan JJ, Morton IJ. Peripheral vascular resistance and angiotensin II levels during pulsatile and non-pulsatile cardiopulmonary bypass. Thorax 1979;34:594-8.

12 Bulkley GB, Oshima A, Bailey RAW. Pathophysiology of hepatic ischaemia in cardiogenic shock. Am $\mathcal{f}$ Surg 1986;151:87-97.

13 Hayes MA, Yau EH, Timmins AC, Hinds CJ, Watson D. Response of critically ill patients to treatment aimed at Response of critically ill patients to treatment aimed at Relationship to outcome. Chest 1993;103:886-95.

14 Nelson DP, King CE, Dodd SL, Schumacker PT, Cain SM. Systemic and intestinal limits of $\mathrm{O}_{2}$ extraction in the dog. $\mathcal{F}$ Appl Physiol 1987;63:387-94.

15 Anand KJ, Hickey PR. Halothane-morphine compared with high-dose sufentanil for anesthesia and postoperative analgesia in neonatal cardiac surgery. N Engl f Med 1992;326: $-9$.

16 Cork RC, Kramer TH, Dreischmeier B, Behr S, DiNardo A. The effect of esmolol given during cardiopulmonary bypass. Anesth Analg 1995;80:28-40. 